\title{
STUDY ON THE VARIATION OF BED SHEAR STRESS BY USING SWAN MODEL IN CAM RANH BAY AND THUY TRIEU LAGOON
}

\author{
Nguyen Hao Quang ${ }^{1,2 *}$, Pham Khanh Ngoc ${ }^{3}$, Jun Sasaki ${ }^{1}$ \\ ${ }^{1}$ The University of Tokyo \\ ${ }^{2}$ Nha Trang University \\ ${ }^{3}$ National Centre for Hydrometeorological Forecasting \\ E-mail: quangnh@ntu.edu.vn
}

Received: 23-2-2017

\begin{abstract}
Turbidity is an important parameter to assess water quality and is an indicator to determine water pollution. In shallow waters, one of the main causes of turbidity is due to resuspension of bed sediment. This process only occurs when water depth is less than one-half the wave length. Meanwhile wave energy will form shear zone and result in resuspension. Bed shear stress is an important quantity to determine the areas where resuspension phenomenon of bed sediment can occur. In this paper, SWAN model was used to calculate and discuss the spatial variation of bed shear stress, taking into consideration the effects of wind velocity and direction at Cam Ranh bay and Thuy Trieu lagoon. The results show that when the wind speed reaches over $5 \mathrm{~m} / \mathrm{s}$, high bed shear stress occurs at shallow waters for both the Southwest and Northeast monsoons. When wind speed reaches over $13 \mathrm{~m} / \mathrm{s}$, most of the study area is influenced by resuspension.
\end{abstract}

Keywords: SWAN model, resuspension, bed shear stress, Cam Ranh bay, Thuy Trieu lagoon.

\section{INTRODUCTION}

Sediment resuspension depends upon the bed shear stress induced by the flow and the resistance of the bed to erosion [1]. Generally, seabed disturbance occurs as a result of bottom shear stress, the combined force which waves and currents exert on the seafloor [2]. The resistance to erosion depends upon the sediment type and mineralogy, pore and eroding fluid concentration and chemical and biological processes [1]. In coastal water, bed shear stress is composed of the two terms $\tau_{c}$ (currents) and $\tau_{w}$ (wind waves).

Wind induced resuspension of bed sediment occurs frequently in shallow water areas and can result in a large contribution to the total nutrient as well as suspended solid load in their water [3]. Bed shear stress influences interaction between sediment and water, contributes to turbulence and mixing in water column (fig. 1). Based on those, the study on the variation of bed shear stress is needed to understand the mechanisms that are the main cause of resuspension in shallow waters.

If the wave height $\left(H_{S}\right)$ is sufficiently large when the water depth $(h)$ is shallow, the orbit of moving water particles creates a shear force on the bay bottom great enough to move the bed sediment [3]. The magnitude of the stress that causes resuspension in the shear zone along the bottom is a function of wave length and water depth and is generally sufficient to begin resuspension when water depth is less than one-half the wave length [3]. 


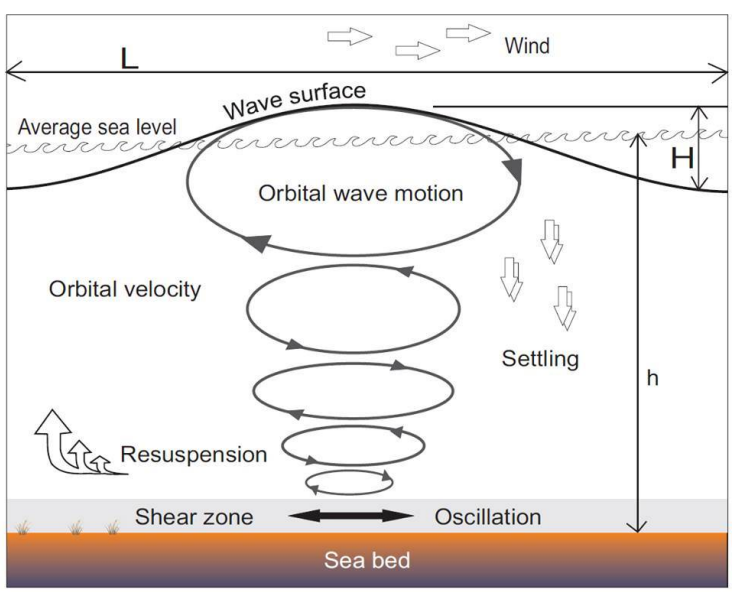

Fig. 1. Schematic diagram of mechanism of turbid water in shallow areas

In order to understand the origin of turbidity induced by resuspension of bed sediment in shallow waters bed shear stress was investigated. As the typical shallow coastal waters in Vietnam, Cam Ranh bay and Thuy Trieu lagoon were the study area.

\section{Wave estimation using SWAN}

SWAN (Simulating Waves Nearshore) developed by Delft University the Netherlands is a third-generation wave model, discrete spectral wave model that describes the evolution of the two dimensional wave energy spectrum in arbitrary conditions of wind, currents, and bathymetry [4]. This model is to obtain realistic estimates of wave parameters for small-scale, coastal regions with shallow water, (barrier) islands, tidal flats, local wind, and ambient currents are verified in stationary mode with measurements in five real field cases $[4,5]$. The governing equation of the SWAN model is based on the wave action balance equation with sources and sinks:

$$
\begin{aligned}
\frac{\partial}{\partial t} N & +\frac{\partial}{\partial x} C_{x} N+\frac{\partial}{\partial y} C_{y} N \\
& +\frac{\partial}{\partial \sigma} C_{\sigma} N+\frac{\partial}{\partial \theta} C_{\theta} N=\frac{S}{\sigma}
\end{aligned}
$$

Where $t$ is time and $N(\sigma, \theta, x, y, t)$ is the action density as a function of intrinsic frequency $\sigma$, direction $\theta$, and horizontal coordinates of $x$ and $y$.
The first term on the left-hand side represents the local rate of change of action density in time, the second and third terms represent propagation of action in geographical $x, y$ direction, respectively (with propagation velocities $C_{x}$ and $C_{y}$ ). The fourth term is the shifting of the relative frequency due to variations in depths and currents. The fifth term represents depth and current-induced refraction. The term $S(\sigma, \theta, x, y, t)$ at the right-hand side is the source term representing generation, dissipation and non-linear wave-wave interactions [4].

\section{METHODOLOGY AND MATERIALS}

\section{Estimated bed shear stress}

There is a variety of models developed for predicting wave induced or wave and current induced bed shear stress [2]. In this research, Sheng and Lick method was applied to estimate bed shear stress caused by wind. This is determined by calculating the maximum horizontal velocity at the edge of the bottom boundary layer and bottom wave periods generated by a Simulating Waves Nearshore (SWAN) model version 41.01AB [4]. The development of wind waves in coastal waters of SWAN model is based on the balance between wind energy input, wave energy and wave energy dissipation [1].

In Cam Ranh bay and Thuy Trieu lagoon, tidal current is dominant with small speed, $0.15 \mathrm{~m} / \mathrm{s}$ in dry season and 0.25 in rainy season [6]. Because the current speed is small and water depth is shallow, the bed shear stress due to wind waves can be much larger than that due to currents [7]. Based on those, bed shear stress is assumed to be caused by wind wave only. Therefore, this is described by the equation of Sheng and Lick (1979) [8].

$$
\begin{gathered}
U_{\max }=\frac{2 \pi H_{S}}{T_{S} \sinh \left(\frac{2 \pi h}{L}\right)} \\
\tau=\frac{1}{2} \rho f U_{\text {max }}^{2}
\end{gathered}
$$


Where: $U_{\max }$ is the maximum bottom boundary velocity; $H_{S}$ is the significant wave height; $h$ is water depth; $\tau$ is the bed shear stress $\left(\mathrm{dyn} / \mathrm{cm}^{2}\right)$; $\rho$ is water density $=1025 \mathrm{~kg} / \mathrm{m}^{3} ; T_{S}$ is the wave period; $L$ is the wave length in shallow waters; $f$ is a dimensionless skin friction coefficient, equal to $1 / \mathrm{Re}$, and approximately 0.004 [8].

By using SWAN model, significant wave height, wave period as well as wavelength are calculated as equations 4, 5 and 7 respectively. The water depth is the input file of the model. Significant wave height, denoted as $H_{S}$ in meters, is defined as:

$$
\begin{gathered}
H_{S}=4 \sqrt{\iint E(w, \theta) d w d \theta} \\
T_{S}=\frac{\sqrt{2 \int_{0}^{2 \pi} \int_{0}^{\infty} \frac{1}{\sinh ^{2} k d} E(\sigma, \theta) d \sigma d \theta} \pi \sqrt{2}}{U_{r m s}} \pi r^{2} \\
U_{r m s}=\sqrt{2 \int_{0}^{2 \pi} \int_{0}^{\infty} \frac{\sigma^{2}}{\sinh ^{2} k d} E(\sigma, \theta) d \sigma d \theta} \\
L=2 \pi\left(\frac{\iint k^{p} E(\sigma, \theta) d \sigma d \theta}{\iint k^{p-1} E(\sigma, \theta) d \sigma d \theta}\right)^{-1}
\end{gathered}
$$
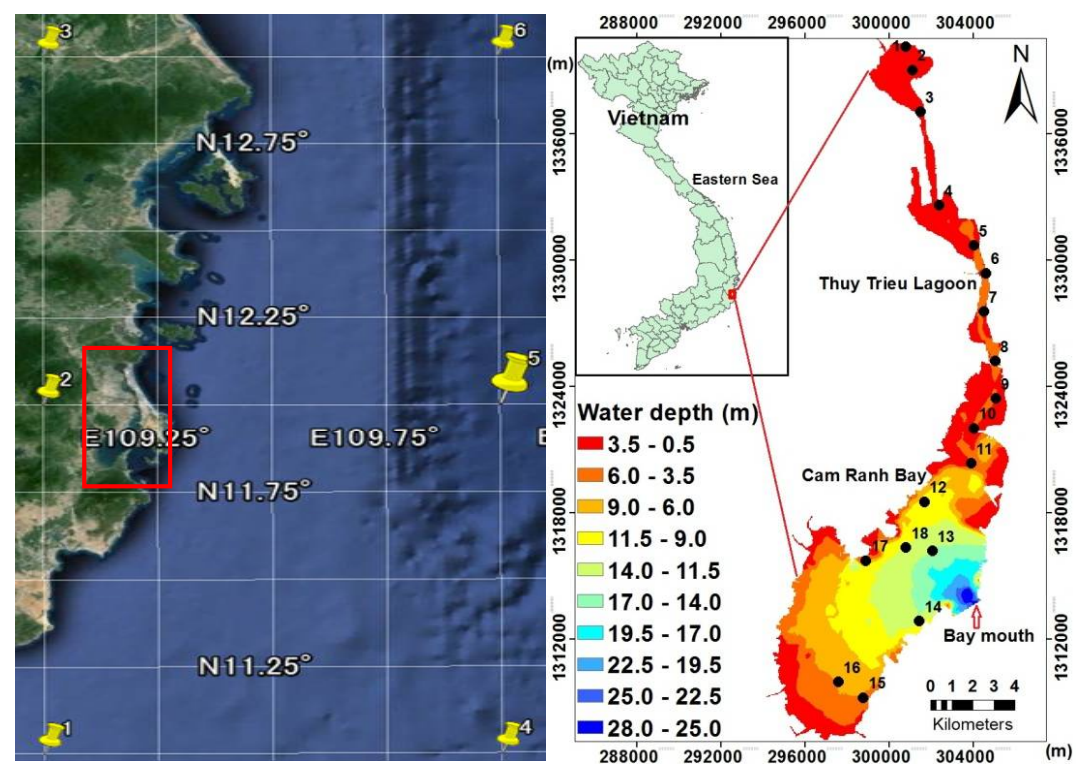

Fig. 2. The locations of wind dataset downloaded from NCEP FNL and geophysical domain of study area
Where $E(w, \theta)$ is the variance density spectrum and $w$ is the absolute radian frequency determined by the Doppler shifted dispersion relation. As default, $\rho$ is equal to 1 [4]. $\sigma$ and $\theta$ are described in equation 4 above.

\section{Data collection}

Wind data is one of the important input parameters for SWAN model. There was a limitation in this study that was the lack of observed data including wind and precipitation. Measured wind data was very few and discontinuous in the study site. Wind dataset including wind speed and its direction was downloaded from National Centers for Environmental Prediction Final (NCEP FNL) Operational Model Global Tropospheric Analyses, continuing from July 1999. Grid cell is $1^{\circ} \times 1^{\circ}$ from $0 \mathrm{E}$ to $359 \mathrm{E}$ and $90 \mathrm{~N}$ to $90 \mathrm{~S}(360 \times 181$ Longitude/Latitude) prepared operationally every six hours. There is a variety of spatial resolutions of wind dataset from 0.25 $\times 0.25$ degrees to $1.25 \times 1.25$ degrees that depends on the regions as well as territories. The highest resolution for wind data in Cam Ranh bay that is available is $1^{\circ} \times 1^{\circ}$ with $6 \mathrm{hr}$ interval. In this study, wind dataset with $1^{\circ} \times 1^{\circ}$ spatial resolution was exploited (fig. 2). 
Bathymetric data was obtained from Institute of Oceanography with $200 \mathrm{~m}$ resolution. The bathymetry for all the model domains had been interpolated using ArcGIS 10.2.2 Spatial Analyst extension tools. After interpolation, bathymetric map was created with $65 \mathrm{~m}$ resolution grid cell for the domain of more than $550,386,525 \mathrm{~m}^{2}$. In order to study the correlation between turbidity and resuspension of bed sediment, AAQ was used to measure turbidity. The AAQ is a cabled multi-parameter water-quality meter because it can measure not only turbidity but also DO, chlorophyll, $\mathrm{pH}, \ldots$ Only turbidity was measured and recorded by AAQ in Cam Ranh bay and Thuy Trieu lagoon.

\section{Setting control files}

SWAN Cycle III version 41.01AB for windows was used in this study for wave simulation within Cam Ranh bay and Thuy Trieu lagoon. In setting control file, seven main parts were created. In this study, the distributions of significant wave height, wave period and wavelength were calculated and investigated. All of them were used to compute bed shear stress for determining resuspension of bed sediment, which affects turbidity distribution in shallow waters. In oder to assess the sensitivity of bed shear stress, wind direction change every 10 degrees was exploited.

In the model, the boundaries of the computational grid in SWAN are both land and water. In case of land there was no problem [6]. All incoming wave energies were absorbed along the coastlines, hence the model assumed no wave generation in this area because Cam Ranh bay and Thuy Trieu lagoon are enclosed by land and only exchange with ocean water via a narrow bay mouth. However, for this narrow bay mouth, the model boundaries were placed far away from the area of interest, more than $10 \mathrm{~km}$. It, therefore, was assumed that waves could freely leave the computational domain.

In this study, the SWAN ran in thirdgeneration mode for wind input, quadruplet interactions, and whitecapping. Triads, bottom friction and depth-induced breaking were activated by this command. Komen was applied as an expression for exponential term for the wave growth by wind.

The output parameters were requested in a two dimensional plot that could be exported in text files. In those, significant wave height, wave direction, wind speed and wind direction and maximum of the orbital motion near the bottom were performed. FORTRAN language was used to convert text file into TECPLOT readable software. The result was presented on TECPLOT software version 10 downloaded free trial (http://www.tecplot.com/).

\section{Statistical evaluation}

The Root Mean Square Error (RMSE) and Scatter Index (SI) were used to quantify the performance of the computed data [4].

If $x i$ is the measured value at the time step i, $y_{\mathrm{i}}$ is the simulated value at the same time step and the $\mathrm{N}$ is time step, then we have:

$$
\begin{aligned}
& R M S E=\sqrt{\sum_{i=1}^{N} \frac{\left(x_{i}-y_{i}\right)^{2}}{N}} \\
& S I=\sqrt{\sum_{i=1}^{N} \frac{\left(x_{i}-y_{i}\right)^{2}}{\sum_{i=1}^{N} N}}
\end{aligned}
$$

\section{RESULTS}

\section{Wind verification}

In this study, wind was considered the most important input data for SWAN simulation because waves were mainly induced by wind. Due to the lack of measured significant wave height data, only observed wind was used to verify the input files. However, measured wind data was very few and discontinuous in Cam Ranh bay and Thuy Trieu lagoon. Besides, it was very difficult to collect observed wind data because it belonged to many sources from many different projects.

Observed wind speed obtained from Institute of Oceanography was used to verify wind data downloaded from NCEP FNL. The comparison between observed and estimated wind speeds is presented in fig. 3 . 


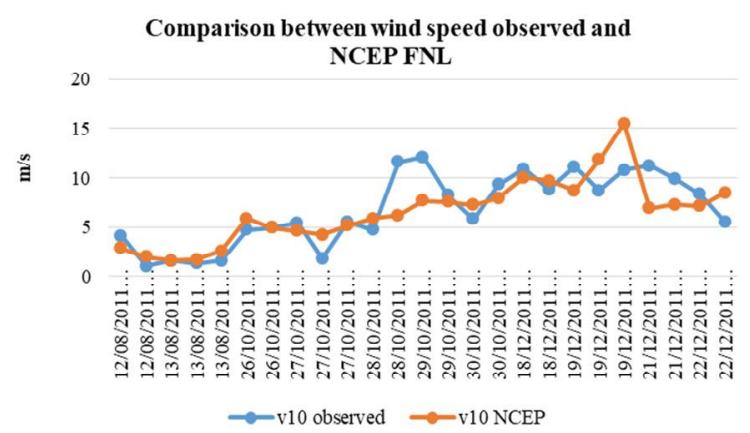

Fig. 3. The comparison between observed and estimated wind speeds

The average observed and estimated wind speeds were 6.77 and 6.55 respectively. RMSE (2.39) and SI (0.35) values were small and acceptable. It meant that the difference between observed and downloaded wind data was quite small. These results showed high consistency between observed and estimated wind speed at $10 \mathrm{~m}$ height. Based on those, wind speed at
$10 \mathrm{~m}$ height downloaded from NCEP FNL was appropriate and could be used in this study with high precision.

\section{Spatial variation of bed shear stress}

In order to largely determine resuspension of bed sediment area, bed shear stress (Tau) was calculated based on wave spectrum. Significant wave height, wave period, wavelength, orbital velocity near the bottom and bed shear stress were computed by SWAN model. As mentioned in method part, bed shear stress is a function of wavelength and water depth and when the water depth is less than one-half the wave length, resuspension occurs. In other words, high bed shear stress will create resuspension of bed sediment, which causes turbidity in shallow waters. The patterns of bed shear stress in dry and rainy seasons are presented in fig. 4.
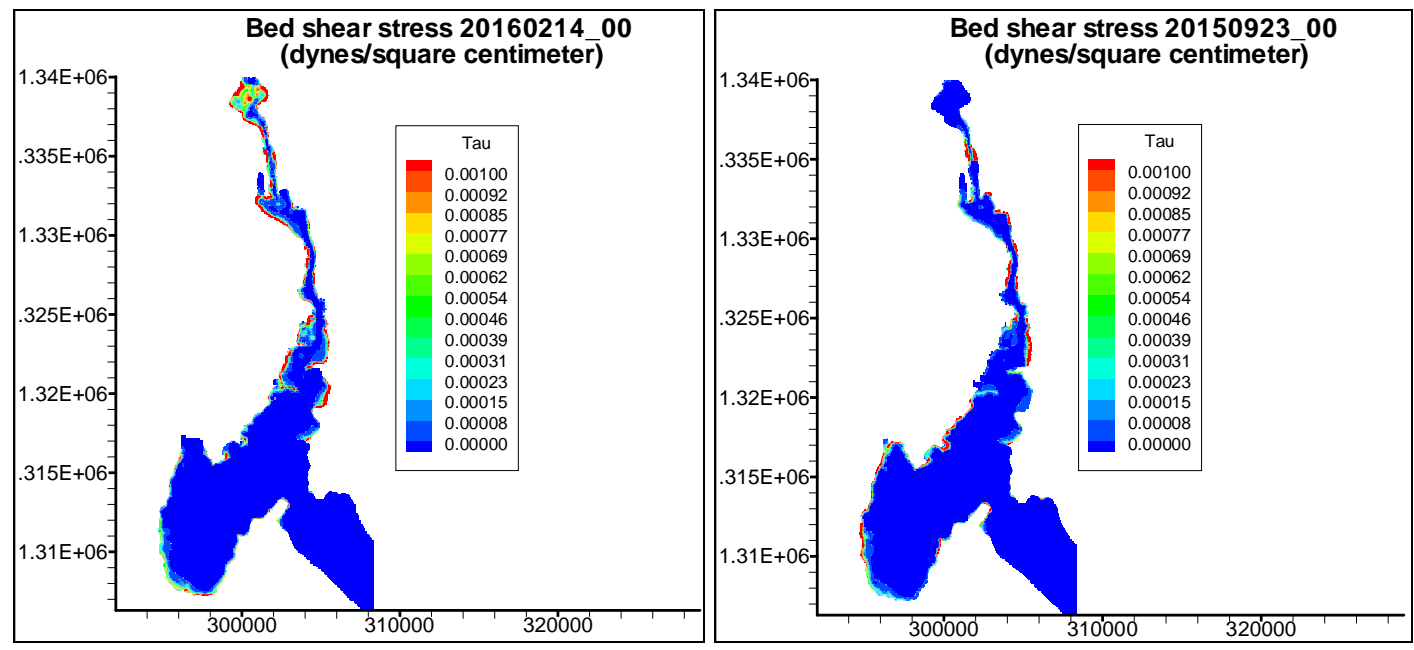

Fig. 4. The typical patterns of bed shear stress in dry (left) and rainy seasons (right)

In dry season, bed shear stress was high in shallow waters, Thuy Trieu lagoon, and coastlines but very low in deep waters, Cam Ranh bay. However, only coastlines showed high bed shear stress in rainy season.

According to the pattern of bed shear stress on Sep. 23, 2015 (rainy season), resuspension of bed sediment might occur only near the coastlines. In contrast, resuspension appeared not only in coastlines but also in shallow waters of Thuy Trieu Lagoon in dry season. The differences of two patterns might be explained by the changes of both wind speed and direction from dry to rainy seasons.

\section{DISCUSSION}

\section{Sensitivity of wave spectrum to wind speed}

To determine the variations of significant wave height, orbital velocity near the bottom (Ubot) and bed shear stress to wind speed, they 
were performed in dry and rainy seasons, SW and NE monsoons respectively. Based on those, two scenarios were developed for dry and rainy seasons corresponding to wind speeds at $1,3,5,7,9,11$ and $13 \mathrm{~m} / \mathrm{s}$. Those values were obtained based on the statistical wind dataset for a long term from 1999 to 2015.

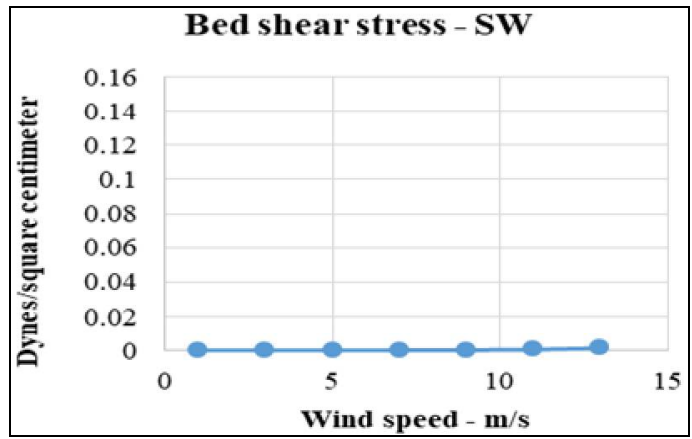

Fig. 5. The variations of bed shear stress to wind speed in SW (left) and NE monsoons (right) at 296437.06 lat. 1308613.36 long

During SW monsoon, when wind speed was greater than or equal to $5 \mathrm{~m} / \mathrm{s}$, high bed shear stress occurred in shallow waters and coastlines. However, in deep waters as Cam Ranh bay, wind speed that was less than $7 \mathrm{~m} / \mathrm{s}$ could not create high bed shear stress. The centre of the study area was most sensitive to the changes of wind speed. When wind speed was greater than $7 \mathrm{~m} / \mathrm{s}$, most of entire study area showed high bed shear stress. The variation of bed shear stress regarding changes of wind speed in NE monsoon is shown in fig. 5 (right).

Wind speed that was greater than or equal to $5 \mathrm{~m} / \mathrm{s}$ could create a large area with high bed shear stress regarding resuspension during NE monsoon. In deep waters, resuspension might occur when wind speed was greater than $7 \mathrm{~m} / \mathrm{s}$. When wind speed reached $13 \mathrm{~m} / \mathrm{s}$, most of the study area showed high bed shear stress including deep areas as Cam Ranh bay.

\section{Sensitivity of wave spectrum to wind direction}

Aside from the dependence on wind speed, the sensitivity of significant wave height, orbital velocity near the bottom and bed shear
The variation of bed shear stress corresponding to the changes of wind speed in SW monsoon is shown in fig. 5. The value of bed shear stress corresponding to wind speed of $1 \mathrm{~m} / \mathrm{s}$ was very small, approximately 0 . It meant that wind speed at $1 \mathrm{~m} / \mathrm{s}$ could not create shear zone in Cam Ranh bay and Thuy Trieu lagoon.

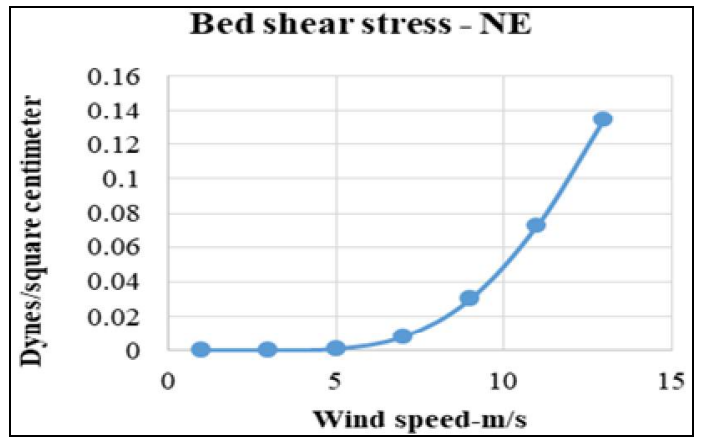

stress to the changes of wind direction were simulated. As analyzed from NCEP FNL, wind speed from $5 \mathrm{~m} / \mathrm{s}$ to $9 \mathrm{~m} / \mathrm{s}$ was dominant from 1999 to 2015. Moreover, SW and NE were the main directions of wind in dry and rainy seasons respectively. Based on those, wind speed at $7 \mathrm{~m} / \mathrm{s}$ was used to assess the sensitivity of wave spectrum to wind direction in every 10 degree change. The variation of bed shear stress corresponding to the variation of wind direction is illustrated in fig. 6 .

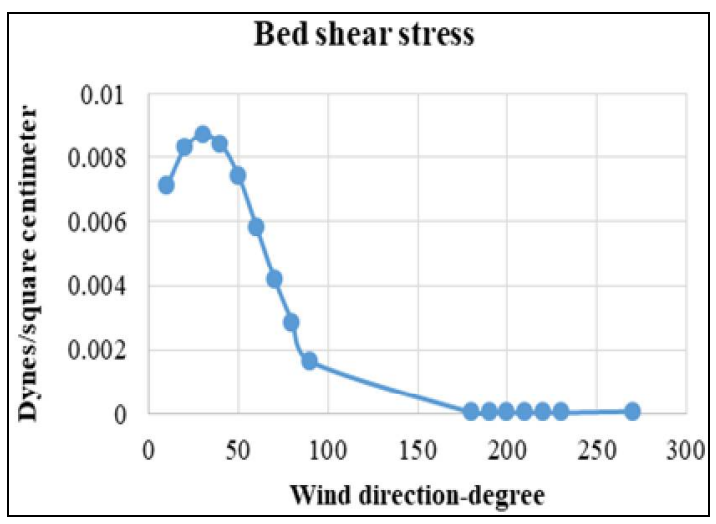

Fig. 6. The sensitivity of bed shear stress according to wind directions at 296437.06 lat. 1308613.36 long 
According to the fig. 6, the amount of resuspension was influenced not only by wind speed but also by wind direction. The simulation results showed that $\mathrm{SW}$ winds caused less resuspension than NE winds in deep waters, Cam Ranh bay. In the upper part of Thuy Trieu lagoon and the centre of the study area, shallow waters were much effected by resuspension in both SW and NE monsoons. At the bay mouth where the water depth was around $30 \mathrm{~m}$, the bed shear stress was always small, approximately 0 in both $\mathrm{NE}$ and $\mathrm{SW}$ monsoons.

\section{Wind regarding resuspension}

During the dry season, low turbidity created by resuspension of bed sediment appeared in most of the study area except shallow waters and coastlines. At the top of the study area, Thuy Trieu lagoon, turbidity was always slightly higher than that in Cam Ranh bay, especially at the centre of the lagoon. It is worth noting that the water depth of this area was around $0.5 \mathrm{~m}$ to $1.5 \mathrm{~m}$. Turbidity was low near the bay mouth, around 0.1 FTU to 1 FTU, and lower than that at the top of Thuy Trieu lagoon. High turbidity in shallow waters and coastlines were mainly caused by resuspension of bed sediment from the bottom. In other words, turbidity measured in shallow waters was closely linked to bathymetry, because bed shear stress that is responsible for local resuspension decreases with increasing water depth [9].

It was stressed that almost no water flows [6] on the rivers surrounding the study area entered into the bay and lagoon because they were controlled by dams at the top of these rivers. There were no turbidity sources supplying to Cam Ranh bay and Thuy Trieu lagoon from the surrounding lands. Furthermore, wind speed under normal condition was not strong enough to create the shear zones in deep waters, Cam Ranh bay. Therefore, resuspension of bed sediment occurred only in shallow waters as Thuy Trieu lagoon and coastlines, and induced high turbidity.

Furthermore, according to the results from SWAN simulation, wind speed that was less than $9 \mathrm{~m} / \mathrm{s}$ was not the major factor affecting turbidity in depth areas. This result may be in favor of the results of previous study in a case study in China [10]. SWAN simulation results also showed that only when wind speed was greater than or equal to $9 \mathrm{~m} / \mathrm{s}$, it could cause shear zone, resuspension of bed sediment in deep waters, Cam Ranh bay. However, for the closed water area as Cam Ranh bay and Thuy Trieu lagoon, wind speed was usually less than $9 \mathrm{~m} / \mathrm{s}$.

\section{CONCLUSIONS}

To our knowledge, our numerical simulation analysis is the first study to understand the spatial variation of bed shear stress as well as resuspension of bed sediment. Due to the lack of tidal data, this study did not discuss the influences of tidal regime on water depth. Bed shear stress value was sensitive to both wind speed and direction. In terms of space, archived results showed that bed shear stress was high in shallow waters, Thuy Trieu lagoon, and coastlines but very low in deep waters, Cam Ranh bay. However, only coastlines showed high bed shear stress in rainy season. This difference might be caused by the changes of wind speed and direction. In Thuy Trieu lagoon, shallow water and coastlines, resuspension occurred when wind speed was greater than $5 \mathrm{~m} / \mathrm{s}$ and it caused high bed shear stress when wind speed was greater than $7 \mathrm{~m} / \mathrm{s}$ in both SW and NE monsoons. Meanwhile, at Cam Ranh bay, resuspension of bed sediment occurred when wind speed was greater than $7 \mathrm{~m} / \mathrm{s}$ during SW monsoon. However, during $\mathrm{NE}$ and SW monsoons, when wind speed reached $13 \mathrm{~m} / \mathrm{s}$, high bed shear stress occurred in both shallow and deep waters.

Acknowledgements: I would like to thank Dr. Nguyen Huu Huan, Head of Department of Marine Ecology, Institute of Oceanography, Vietnam, who always believes me and has shared precious dataset in the study area.

\section{REFERENCES}

1. Schwartz, M. (Ed.), 2006. Encyclopedia of coastal science. Springer Science \& Business Media.

2. Dalyander, P. S., Butman, B., Sherwood, C. R., Signell, R. P., and Wilkin, J. L., 2013. 
Characterizing wave-and current-induced bottom shear stress: US middle Atlantic continental shelf. Continental Shelf Research, 52, 73-86.

3. Laenen, A., and LeTourneau, A. P., 1996. Upper Klamath Basin nutrientloading study: Estimate of wind-induced resuspension of bed sediment during periods of low lake elevation (No. 95-414). US Geological Survey.

4. Ris, R. C., Holthuijsen, L. H., and Booij, N., 1999. A third-generation wave model for coastal regions: 2. Verification. Journal of Geophysical Research: Oceans, 104(C4), 7667-7681.

5. SWAN team, 2015. User manual: SWAN Cycle III version 41.01AB. http://swanmodel.sourceforge.net/download /zip/swanuse.pdf.

6. Phan, T. B., 2012. Simulation of the transmission of pollutants under impacts of dynamic factors in Cam Ranh Bay by using numerical model. Master's thesis of De- partment of Meteorology, Hydrology and Oceanography, Hanoi University of Science. http://hus.vnu.edu.vn/files/ChuaPhanLoai/LuanVanThacSi-ChuaPhanLoai\%20(423).pdf.

7. Zheng, G. J., 2007. Hydrodynamics and water quality: modeling rivers, lakes, and estuaries. ISBN 978-0-470-13543-3. A John Wiley \& Sons, Inc. Publishcation.

8. Sheng, Y. P., and Lick, W., 1979. The transport and resuspension of sediments in a shallow lake. Journal of Geophysical Research: Oceans, 84(C4), 1809-1826.

9. Ouillon, S., Douillet, P., and Andréfouët, S., 2004. Coupling satellite data with in situ measurements and numerical modeling to study fine suspended-sediment transport: a study for the lagoon of New Caledonia. Coral Reefs, 23(1), 109-122.

10. Yu, Y., Zhang, H., and Lemckert, C., 2014. Salinity and turbidity distributions in the Brisbane River estuary, Australia. Journal of hydrology, 519, 3338-3352. 